\title{
Elusive chemistry of hydrogen sulfide and mercaptans in wine
}

Vicente Ferreira (*), Ernesto Franco-Luesma, Eduardo Vela, Ricardo López and Purificación Hernández-Orte

Laboratory for Aroma Analysis and Enology (LAAE), Department of Analytical

Chemistry, Universidad de Zaragoza, Instituto Agroalimentario de Aragón (IA2) (UNIZAR-CITA), c/ Pedro Cerbuna 12, 50009 Zaragoza, Spain

Associated unit to Instituto de Ciencias de la Vid y el Vino, (Universidad de La RiojaCSIC-Gobierno de la Rioja)

* To whom correspondence should be addressed

Phone: +34976 762067

Fax: +34 976761292

Email: vferre@unizar.es 


\begin{abstract}
This paper summarizes, discusses and complements recent findings about the fate of $\mathrm{H}_{2} \mathrm{~S}$ and methanethiol $(\mathrm{MeSH})$ during wine storage. Analytical assays to determine free volatile sulfur compounds (VSCs) and brine-releasable (BR-) VSCs in combination with accelerated reductive (AR) aging and micro-oxygenation (MOX) assays allow characterizing the different categories of species able to produce $\mathrm{H}_{2} \mathrm{~S}$ and $\mathrm{MeSH}$ and the processes of interconversion. Each wine seems to contain a specific total amount of $\mathrm{H}_{2} \mathrm{~S}$ and $\mathrm{MeSH}$ distributed into free, metal-complexed and oxidized forms (di and polysulfides) interconnected through reversible redox equilibria whose external expression is wine redox potential. Oxidation transforms all mercaptans likely into nonvolatile disulfides and hydrodisulfides. In anoxia, these molecules are spontaneously and quantitatively reduced back. The concomitant accumulation of major wine thiols would provoke complex dissociation and the release of free $\mathrm{H}_{2} \mathrm{~S}$ and MeSH. Additionally, total amounts can increase due to the metal-catalyzed desulfhydration of cysteine and methionine.
\end{abstract}

Key words: reductive off odors, sulfides, disulfides, copper, iron, 


\section{INTRODUCTION}

2 In wine science, reduction refers to a series of off-odors related to an array of sulfur

3 compounds displaying characteristic notes such as rotten eggs, decaying seaweed,

4 putrefaction or cooked cabbage. ${ }^{1}$ These off-odors are of great concern in the wine

5 industry, since they can develop after the wine has been bottled when no remedial action

6 is possible. ${ }^{2}$ It has been estimated that they constituted nearly a third of the faults

7 encountered in the wines sent to one of the largest international contests.3(Goode/Harrop)

8 These off-odors are primarily caused by the sulfhydryl compounds (-SH) $\mathrm{H}_{2} \mathrm{~S}$ and $\mathrm{MeSH}$,

9 and eventually other mercaptans and volatile sulfur compounds (VSCs). ${ }^{1}$ They are normal

10 by-products of alcoholic fermentation ${ }^{4,5}$ but they are easily purged out by the stream of

$11 \mathrm{CO}_{2}$ produced during fermentation and, in most cases, only little subthreshold levels

12 remain not posing any sensory problem. However, in a number of situations related to

13 different causes, such as N-deficient musts, ${ }^{5}$ specific strains of yeasts, ${ }^{6}$ or less frequently,

14 B group vitamin deficiencies, or a too high protein or glutathione level in must7,8

15 suprathreshold levels of these compounds can accumulate. Additionally, the widespread

16 use of reductive winemaking techniques in which the contact of $\mathrm{O}_{2}$ is minimized

17 throughout the winemaking process has increased the frequency of appearance of this

18 problem. ${ }^{9}$ If these compounds are formed, winemakers decrease their levels by copper

19 fining, aeration or addition of lees. ${ }^{10-13}$ In general, these remedial actions have an

20 immediate impact decreasing the intensity of the sensory problem, but their long term

21 effectiveness is under question. By experience, winemakers know that once a wine shows

22 a tendency to develop reductive off-odors, it seems to become susceptible to suffer this

23 problem again during its shelf-life, ${ }^{14}$ particularly when it is stored in a bottle closed with

24 a closure with low permeability to oxygen. ${ }^{15}$ This suggests that these treatments affect the 
odor-active molecules but not to their different precursors. Up to this date, these precursors have not been identified.

One reason why the progress in research is being so difficult lies in the complicated chemistry of sulfur. This element can be present in different redox states, has the ability to concatenate making bonds with itself and can form a large number of combinations not only with carbon atoms, but with some metal cations present at low concentrations in wine, such as copper, iron or zinc. Furthermore, small molecules or simple complexes tend to aggregate forming clusters containing $\mathrm{S}$ atoms in different redox states. ${ }^{16-18}$ Additionally, the long time span required to observe the capricious appearance of reductive off-odors during wine aging has not helped. This complicated scenario has just recently begun to be understood when new chemical assays have made it possible to recognize the existence of different species of these molecules interconnected via different chemical equilibria ${ }^{19-23}$. Additional recent works revealing key details about the interactions between sulfides, copper, iron and oxygen ${ }^{18,22-24}$ have provided an essential theoretical framework to understand the relationship between the different species.

The present paper summarizes the most relevant recent findings and adds new complementary experimental material or data analyses essential for understanding unclear aspects. With all the pieces at hand, a basic theoretical model explaining the underlying chemistry of these deleterious molecules has been formulated.

\section{Basic tools for the study of the processes related to reductive off-odors}

Three different categories of analytical strategies have to be used in combination in order to get enough information about the species related to reductive problems:

1. Direct headspace methods analyzing vapors on the undisturbed, undiluted wine sample for measuring exclusively free forms of $\mathrm{H}_{2} \mathrm{~S}$ and mercaptans. ${ }^{20,25}$ It should 
be noted that strategies commonly used to gain sensitivity, such as the addition of salt $^{1,26}$ or SPME preconcentration ${ }^{26-27}$ will affect equilibria between free and complexed forms which could bias the results.

2. Brine-dilution headspace methods. Two different strategies have been so far proposed. In the first one the vapors emanated from the wine strongly diluted in brine are pre-concentrated in a SPME fiber. ${ }^{20,28}$ The second strategy concentrates the headspace on the brine-diluted wine directly on a gas adsorbing tube. ${ }^{19}$ Since no redox reagents are involved, it can be assumed that only species in which sulfur is already as sulfide -complexes with metal cations and the free sulfhydryl fraction- will be detected in this brine releasable (BR) fraction. The complexed fraction can be obtained simply by subtracting the free fraction from the BRfraction. Alternatively, it is possible to calculate the quotient between free and BR-forms, $\alpha$, which provides the percentage of sulfide under free form. In previous works, the BR-fraction was improperly referred as the "total" fraction $^{20,21,29}$ because in many commercial red wines it remained relatively stable during reductive aging. Recent works with un-bottled or recently microoxygenated wines ${ }^{12,23}$ have revealed, however, that these BR fractions are not stable and that therefore cannot be referred to as "total".

3. Accelerated reductive (AR) assays. Two different types of these assays have been proposed. The first one consists of heating a volume of wine in a completely anoxic environment for some weeks; ${ }^{21}$ the second one involves the addition of a strong reducing agent such as TCEP, eventually together with a $\mathrm{Cu}(\mathrm{I})$ chelator, such as BCDA. ${ }^{19,22}$ Then, these reduced wines can be further analyzed by the methods in categories 1 and 2. In the case of the accelerated anoxic strategy, it has been demonstrated that the levels of both free and BR-forms obtained after 12.5 
days at $50^{\circ} \mathrm{C}$ correlate well with the levels of these forms measured in the wines after 1 year of anoxic storage. ${ }^{29}$

\section{Changes in free and BR-forms during anoxic storage}

Increases in free forms and in $\alpha$ : release. The most obvious effect of storing a wine under completely anoxic storage is the increase in the levels of free forms of $\mathrm{H}_{2} \mathrm{~S}$ and $\mathrm{MeSH},{ }^{12,21,23,29}$ which is the cause of the appearance of reductive off-odors. Such increase is due in part to the increase in $\alpha$, the percentage of $\mathrm{H}_{2} \mathrm{~S}$ or MeSH under free forms. This can be clearly seen in Figure 1, which represents the evolution of this parameter during the accelerated anoxic storage of bottled red wines. ${ }^{21}$ Similar results have been observed with other wines and storage conditions ${ }^{12,21,23,29}$ meaning that one of the most relevant processes taking place during anoxic storage of wines is the dissociation of metalcomplexed forms to release free sulfhydryl forms. In bottled red wines release accounted for $90 \%$ of the observed increase in free $\mathrm{H}_{2} \mathrm{~S}$, while in whites and rosé wines it could explain just $24 \%$ of the increases of free $\mathrm{MeSH}^{21}$

Increases in BR-forms. The BR fraction can also suffer relevant changes during aging. This is particularly evident in the case of MeSH, whose BR-levels continuously increase in a fairly linear way during anoxic storage, regardless of the temperature. ${ }^{21,29,30}$ Those increases accounted for $50-75 \%$ of the total increments of free MeSH observed in ARaging and were particularly important in white and rosé wines. At room-temperature, normal bottled wines were found to produce between 3 and $7.5 \mathrm{ng} / \mathrm{L}$ of BR-MeSH per day of anoxic storage. ${ }^{29}$ Wines particularly affected by reductive off-odor problems will likely form higher amounts. These increases in BR-forms were attributed to the "de novo" formation of $\mathrm{MeSH}$, most likely from the metal catalyzed desulfhydration of methionine, ${ }^{30}$ as will be later confirmed. 
100 The evolution of BR-forms of $\mathrm{H}_{2} \mathrm{~S}$ during anoxic aging is more complex and at least three

101 clearly different patterns can be identified in the literature, ${ }^{12,21,23,29}$ as summarized in

102 Figure 2. The figure shows data from a normal bottled red wine taken from reference ${ }^{21}$

103 and from two other cases taken from reference. ${ }^{12}$

104 The stability pattern followed by W1 seems to be the main evolution pattern followed by 105 normal bottled red wines. ${ }^{21}$ Only in 4 out of 16 cases there was a slight $(3-6.7 \mu \mathrm{g} / \mathrm{L})$ 106 increase in BR-levels after 3 weeks of AR-aging. ${ }^{21}$ In white and rosés, however, levels of 107 BR- $\mathrm{H}_{2} \mathrm{~S}$ tended to increase continuous and linearly with aging time (4.6-12.6 $\mu \mathrm{g} / \mathrm{L}$ after 1083 weeks of AR-aging). ${ }^{21}$ The evolution pattern followed by W2 in the figure is expected 109 to be followed by wines having suffered some previous oxidation. W2 (R3 in the 110 reference $^{12}$ ) is a red wine which had been subjected in the cellar to a MOX treatment 2 111 months before the analysis. In this case, $\mathrm{BR}-\mathrm{H}_{2} \mathrm{~S}$ strongly increase during the first 2 weeks 112 of reductive aging, to plateau in the final period. The initial increases are likely due to the 113 reduction of $\mathrm{BR}-\mathrm{H}_{2} \mathrm{~S}$ forms previously oxidized during the MOX treatment. ${ }^{23}$ Finally,

114 W2_Cu is this same wine after a copper fining treatment which left a final copper content 115 close to $0.5 \mathrm{mg} / \mathrm{L}$. In this case, $\mathrm{BR}-\mathrm{H}_{2} \mathrm{~S}$ forms continuously increase during the complete 116 aging process reaching values well above those observed for W2, suggesting that 117 increased levels of copper induce a "de novo" formation of BR-forms.

118 Therefore, increases in BR-forms seem to have two different sources:

119 1. The reduction of previously oxidized BR-forms ${ }^{23}$

1202 2. The "de novo" production likely from amino acids

121 This second possibility will be specifically addressed in the following section.

123 De novo formation of $\mathrm{H}_{2} \mathrm{~S}$ and $\mathrm{MeSH}$ from metal catalyzed desulfhydration of S124 amino acids. The metal catalyzed desulfhydration of S-amino acids has been 
125 demonstrated to occur in aqueous solutions at high temperatures. ${ }^{31}$ In wine, the likely

126 involvement of cation metals in the formation of $\mathrm{H}_{2} \mathrm{~S}$ and $\mathrm{MeSH}$ has been previously

127 observed. ${ }^{12-14}$ In another report, increases of BR-MeSH in some samples were correlated

128 to the levels of methionine and aluminum of the wine. ${ }^{30}$

129 Additional clues about the involvement of S-amino acids and metals on the accumulation

130 are found in Table 1. The table summarizes results from a PLS-modeling carried out on 131 data reported in reference ${ }^{21}$ relating increases of BR-forms to the wine chemical 132 composition. Although the models are complex, they reveal the existence of an evident

133 link between increases of $\mathrm{BR}-\mathrm{H}_{2} \mathrm{~S}$ and $\mathrm{BR}-\mathrm{MeSH}$ and the corresponding $\mathrm{S}$ - containing 134 amino acids, and in some cases, also with metals. The model for red wines (1, Table 1) 135 suggests that the de novo production of $\mathrm{H}_{2} \mathrm{~S}$ is positively related to the cysteine content 136 of the wine. In the case of whites and rosés the model is more explicit (2, Table 1$)$ and 137 suggests that increases in $\mathrm{BR}-\mathrm{H}_{2} \mathrm{~S}$ are basically the result of the metal catalyzed 138 desulfhydration of cysteine. Similarly, the accumulation of BR-MeSH in red (3, Table 1) 139 and white and rosé wines (4, Table 1) are related to the wine levels of methionine, and in 140 the case of white and rosé wines, also to metals.

141 Finally, results of an experiment specifically carried out to check the ability of metal 142 cations to catalyze the desulfhydration of cysteine and methionine are summarized in 143 Figure 3. Results confirm that copper can significantly induce the formation of BR-forms 144 of these VSCs and that polyphenols are essential for the catalytic reaction (data not 145 shown). The negative effects played by $\mathrm{Mn}$ and $\mathrm{Al}$, as suggested in model 2 (Table 1), 146 were also confirmed, while the effects of $\mathrm{Fe}$ and $\mathrm{Zn}$ on $\mathrm{H}_{2} \mathrm{~S}$ and $\mathrm{MeSH}$ formation were 147 not. The understanding of the specific effects played by metal cations and their different 148 chelators including polyphenols, will have to be addressed in future research. 


\section{Pools of species precursors of free $\mathrm{H}_{2} \mathrm{~S}$ and $\mathrm{MeSH}$}

151 Taking into account all the previous elements, it can be concluded that the tendency of a specific wine to release free $\mathrm{H}_{2} \mathrm{~S}$ and $\mathrm{MeSH}$ during reductive aging depends on its content in three different pools of compounds:

1. BR-forms (free plus metal complexed forms)

2. Oxidized precursors, such as disulfides or polysulfides

3. Cysteine, methionine and other S-containing species together with a catalytic system able to induce their desulfhydration. This pool is particularly important in MeSH production

160 desulfhydration can take place simultaneously during AR-aging. A fine assignment will

161 require the use of chemical reducing agents, such as TCEP, ${ }^{19,22}$ after demonstrating that

162 they not promote desulfhydration, and/or specific HPLC-MS strategies devoted to 163 measure oxidized precursors. ${ }^{22}$

164 Leaving aside the catalytic systems able to induce "de novo" formation, it can be 165 considered that each wine contains a fixed pool of $\mathrm{H}_{2} \mathrm{~S}$ and $\mathrm{MeSH}$, which will be referred 166 as the "present total amount" of these molecules, distributed into three differentiable 167 fractions: free; metal bound; and oxidized precursors. The following part of the paper will 168 be devoted to understand how the three fractions are related.

\section{Wine redox potential}

171 It is important to differentiate between the thermodynamic redox potential and the measured redox potential since this last one will reflect exclusively the redox pairs which are electrochemically active at the surface of the electrode. In the many cases in which

174 the solution contains redox pairs interconnected by non-reversible or very slow reactions 
175 at the electrode surface, the experimentally determined potential will not reflect the true

176 thermodynamic redox potential but a figure related to the potential at which the oxidation

177 and reduction currents in the electrode equilibrate. ${ }^{32}$ Those currents are generated by the

178 redox pairs active in that electrode and will typically evolve as the slow redox reaction

179 progress. $^{33}$ In practice, this means that redox measurements are effective only in

180 anaerobic solutions ${ }^{34}$ or in solutions dominated by iron ions. ${ }^{33,35}$

181 In the case of wine, the redox potential is a standard measurement ${ }^{36}$ whose experimental 182 value strongly depends on wine $\mathrm{pH}, \mathrm{O}_{2}$ concentration, ${ }^{32,37}$ electrode material and ethanol

183 levels, ${ }^{32,38}$ but not on the wine content in polyphenolic antioxidants. ${ }^{39,40}$ In the absence of

$184 \mathrm{O}_{2}$, the changes observed in wine redox potential during its oxidation or reduction seem

185 to be related to the changes in the ratios $\mathrm{Fe}(\mathrm{II}) / \mathrm{Fe}(\mathrm{III})$ and cysteine/cystine (or

186 GSH/GSSG), as will be shown.

187 The effect of cysteine on the redox potential of wine models containing or not copper and

188 iron can be appreciated in Figure 4. In the absence of cysteine and in the presence of $189 \mathrm{Fe}(\mathrm{II})$, the redox potential of the system is around $103 \pm 2 \mathrm{mV}$. The addition of $\mathrm{Cu}(\mathrm{II})$ has 190 no effect on the potential, while the presence of $\mathrm{Cu}(\mathrm{I})$ makes the potential decrease 191 slightly but significantly to $82 \pm 3 \mathrm{mV}$. The addition of cysteine causes a strong decrease 192 in the redox potential, indicating that this amino acid is active in the electrode. The final 193 redox potential depends primarily on the concentration of cysteine and on that of $\mathrm{Fe}(\mathrm{II})$, 194 but the presence of either $\mathrm{Cu}(\mathrm{II})$ or $\mathrm{Cu}(\mathrm{I})$ does not seem to have much effect. The most 195 negative redox potential is attained in the wine model containing only cysteine.

196 The dependence between the redox potential and the molar fraction of reduced forms of 197 a selected number of redox pairs present in wine models is summarized in Figure 5. As 198 can be seen for the three $\mathrm{Fe}(\mathrm{II}) / \mathrm{Fe}(\mathrm{III})$ systems represented in the figure, the redox 199 potential associated to a given redox pair is extremely dependent on the specific 
compositional parameters of the solution. This means that redox potential cannot be used to compare between wines, but still it will be useful to monitor how the main redox pairs present in the wine evolve during oxidation or reduction. Another remarkable observation is that the pair $\mathrm{Fe}(\mathrm{II}) / \mathrm{Fe}(\mathrm{III})$ determines the potential in the right part of the plot $(\mathrm{E}>50$ $\mathrm{mV})$, while the system cysteine/cystine determines redox potential in the left part $(\mathrm{E}<50$ $\mathrm{mV})$.

\section{The pivotal role of redox potential in the distribution of species of $\mathrm{H}_{2} \mathrm{~S}$ and $\mathrm{MeSH}$}

The most obvious change observed during reductive storage of wine is a decrease in the wine redox potential. This can be seen in Figure 6 which represents the evolution of the average redox potentials of two sets of wines during their anoxic storage at $50^{\circ} \mathrm{C} .^{21}$

211 In the case of red wines, there is a continuous decrease during the storage (significant at $\mathrm{P}<10^{-7}$ ), while in whites and rosés the decrease takes place only in the first 12 days of storage (significant at $\mathrm{P}<0.01$ ), while it increases again in the last sampling point

214 (significant at $\mathrm{P}<0.01$ ). Similar results have been obtained in the anoxic storage of wines at room temperature ${ }^{29}$ and in the AR-aging of wines subjected to MOX. ${ }^{23}$ Decreases in

216 the redox potential indicate that wines become enriched in the reduced forms of the redox

217 pairs active at the electrode surface. The source of those electrons is not well understood, but it could be related to the presence in wine of many polyphenols with antioxidant properties which may undergo spontaneous condensation reactions even in strict anoxia. ${ }^{41}$

220 Redox potential plays an essential role determining the relationship between the three differentiable fractions (free; metal bound; oxidized precursors) forming the "present total amount" of $\mathrm{H}_{2} \mathrm{~S}$ and MeSH contained in a wine. 
the BR- $\mathrm{H}_{2} \mathrm{~S}$ levels of the 12 samples -initial wine $+3 \mathrm{MOX}$ samples $+(2 \mathrm{x} 4)$ AR-aging derivatives each- derived from the MOX experiment carried out with this particular wine versus their corresponding measured redox potentials. The three MOX samples are those with redox potentials above $-50 \mathrm{mV}$, while the initial wine and the 8 samples subjected to AR-aging all had negative redox potentials. As discussed in such reference, the figure is completely equivalent to the characteristic sigmoid observed in a redox titration in which a reducing agent $\left(\mathrm{H}_{2} \mathrm{~S}\right)$ is quantitatively oxidized by an oxidant $\left(\mathrm{O}_{2}\right.$ mediated by copper and iron, as suggested $\left.{ }^{18,24}\right)$. It is also most evident the similarity between the sigmoid shown in the plot and the function relating the molar fraction of cysteine to the redox potential shown in Figure 5. The linearization of the sigmoid by means of the logit transformation ${ }^{23}$ suggested that it corresponds to a two-electron reversible redox process with a formal potential around $-82 \pm 2.2 \mathrm{mV}$. Since reduced samples were obtained both from the initial wine and from the MOX samples the process has to be highly reversible, and is consistent with a "total amount" of $\mathrm{H}_{2} \mathrm{~S}$ close to $160 \mu \mathrm{g} / \mathrm{L}$ in this particular wine. Such total amount can be present as BR-forms (sulfide) or as oxidized forms, nondetectable by the BR-method, and the proportion of both forms is determined by the redox potential.

The distribution of BR-forms into free and metal-complexed forms is also determined by the redox potential. This was seen in in references ${ }^{23,29}$ and is further supported in Figure 8 , which shows unpublished data from the experiment described in reference. ${ }^{21}$ The plots represent the average $\alpha$ fractions of free $\mathrm{H}_{2} \mathrm{~S}$ and free MeSH of 16 red wines and 8 whites and rosé wines subjected to AR-aging different times (1.5, 5.5, 12 and 21 days). As was already seen in Figure 6, redox potentials become more negative during AR-aging and, concomitantly, the metal-complexed fraction decreases so that $\alpha$ increases. The close correspondence between $\alpha$ and redox potential suggests that complex formation and 
250 dissociation are also highly reversible processes. This is particularly evidenced by the fact 251 that the reversion in the redox potential suffered by whites and rosé wines after 21 days 252 of AR-aging (see Figure 6) is followed by a decrease in $\alpha$ for $\mathrm{H}_{2} \mathrm{~S}$, as seen in Figure 8.

253 The $\alpha /$ redox potential plots are less sigmoid in shape than those observed in figures 5 and 2547 , which may be compatible with the partial displacement of the complex equilibria by 255 the addition of a competing complexing agent, such as cysteine. Additionally, as reported 256 in reference, ${ }^{23}$ the process of release of free forms by dissociation of metal complexed 257 forms, takes place at potentials significantly slightly more reductive than those at which 258 oxidized precursors are reduced into BR-forms. This observation indicates that in a 259 spontaneous reduction process, the reduction of oxidized precursors takes place before 260 complex cleavage. This in fact could imply that cleavage is the result of the competing action of the wine major thiols (cysteine and glutathione) formed by reduction of their oxidized forms.

263 There are more evidences supporting this hypothesis. First, the amounts of free $\mathrm{H}_{2} \mathrm{~S}$ 264 released after AR-aging in the wines in the reference ${ }^{21}$ are significantly correlated to $1 / \mathrm{C}_{\mathrm{Cu}}$ 265 ( $\mathrm{r}=0.750$ and $\mathrm{r}=0.950$, both significant at $\mathrm{P}<0.001$, for reds and for whites and rosés, 266 respectively) and similar observations have been made in the copper-fining study. ${ }^{12}$ Since 267 among wine cations, copper has highest bonding constants with sulfhydrils, wines containing more copper will release a smaller fraction for an equivalent production of competing thiol. Second, some satisfactory models for predicting the amounts of free $\mathrm{H}_{2} \mathrm{~S}$ 270 and MeSH released from their complexed forms have been derived and are given in Table 2711 (models 5 to 8 ). The two models for $\mathrm{H}_{2} \mathrm{~S}$ suggest that a high release of this molecule will require a high $\mathrm{BR}-\mathrm{H}_{2} \mathrm{~S} / \mathrm{Cu}$ ratio and a low redox potential. In the case of $\mathrm{MeSH}$, a

273 high release requires also high levels of complexed $\mathrm{MeSH}$ and a high complexed $274 \mathrm{MeSH} / \mathrm{Cu}$ ratio. The models support, essentially, that the increases in free forms 
275

276

277

278

279

280 Conclusions, hypotheses and perspectives

281 All the previous facts lead us to formulate the following set of conclusions and 282

responsible for the appearance of reductive off-odors are due to the dissociation of metal complexes induced by a drop in the redox potential. In practice this confirms that the presence of copper makes more difficult and retards (but does not impede) the release of free forms.

\section{hypotheses:}

1. Each wine contains a specific present total amount of $\mathrm{H}_{2} \mathrm{~S}$ and $\mathrm{MeSH}$ distributed into different species. Depending on the wine, such total amount can increase with time due to the metal-catalyzed desulfhydration of cysteine and methionine (de novo formation). De novo formation is a poorly known process which constitutes a relevant and common source of $\mathrm{MeSH}$ and is less frequent and important in the case of $\mathrm{H}_{2} \mathrm{~S}$

2. Such total amounts of $\mathrm{H}_{2} \mathrm{~S}$ and $\mathrm{MeSH}$ are distributed into BR-forms and into oxidized forms interconnected through reversible redox equilibria. These equilibria are of the type:

$$
\begin{gathered}
\mathrm{H}_{2} \mathrm{~S}+\mathrm{RSH} \longrightarrow \longrightarrow \mathrm{RSSH}+2 \mathrm{H}^{+}+2 \mathrm{e}^{-} \\
\mathrm{MeSH}+\mathrm{RSH}<\longrightarrow \text { RSSMe }+2 \mathrm{H}^{+}+2 \mathrm{e}^{-} \\
2 \mathrm{RSH}<\longrightarrow \text { RSSR }+2 \mathrm{H}^{+}+2 \mathrm{e}^{-} \\
\mathrm{H}_{2} \mathrm{~S}+\mathrm{RSSR} \longrightarrow \longrightarrow \text { RSSSR }+2 \mathrm{H}^{+}+2 \mathrm{e}^{-}
\end{gathered}
$$

Where RSH can be cysteine or glutathione, the major thiols of wine, and RSSH is a hydrodisulfide, RSSR is cystine or oxidized glutathione (or the mixed disulfide) and RSSSR is a trisulfide. RSSH and RSSSR are examples of oxidized forms of $\mathrm{H}_{2} \mathrm{~S}$ and RSSMe of MeSH. Formation of some of these putative molecules has been recently described in model solutions and even in wine by Kreitman et al. ${ }^{22}$ The oxidation will follow, most likely, the mechanisms recently described by these same authors. ${ }^{24}$ The 
role played by copper should be complex since the reaction takes place via a copper complex, but some copper complexed forms seem to be quite resistant to oxidation. ${ }^{17,23,42}$

3. The degree of the displacement of the chemical equilibria schematized in the previous paragraph depends on the wine redox potential; or more precisely, impacts the wine redox potential since this parameter seems to depend on the cysteine/cystine (or $\mathrm{GSH} / \mathrm{GSSG}$ ) ratios. At positive redox potentials $(>50 \mathrm{mV})$, most wine mercaptans will be as oxidized forms. It should be considered that Fe(III) and the thiol group cannot be simultaneously present, unless they are strongly protected by complex formation, as can be deduced from the mechanisms proposed ${ }^{24}$ and from previous confirm this, since the residual low levels of $\mathrm{BR}-\mathrm{H}_{2} \mathrm{~S}$ found in the MOX samples with higher redox potentials, were directly correlated to the copper levels of the wine

4. BR-forms of $\mathrm{H}_{2} \mathrm{~S}$ and $\mathrm{MeSH}$ are further distributed into free (odor active) and into metal complexed (odorless) forms. Complexes are mainly with $\mathrm{Cu}(\mathrm{II}), \mathrm{Cu}(\mathrm{I}), \mathrm{Fe}(\mathrm{II})$ and even $\mathrm{Zn}(\mathrm{II})$.

$$
\begin{gathered}
\mathrm{M}^{2+}+\mathrm{H}_{2} \mathrm{~S} \longrightarrow \longrightarrow \mathrm{MS}+2 \mathrm{H}^{+} \\
2 \mathrm{Cu}^{+}+\mathrm{H}_{2} \mathrm{~S} \longrightarrow \longrightarrow \mathrm{Cu}_{2} \mathrm{~S}+2 \mathrm{H}^{+} \\
\mathrm{M}^{2+}+2 \mathrm{CH}_{3} \mathrm{SH}<\longrightarrow \mathrm{CH}_{3} \mathrm{SMSCH}_{3}+2 \mathrm{H}^{+} \\
\mathrm{Cu}^{+}+\mathrm{CH}_{3} \mathrm{SH} \longrightarrow \longrightarrow \mathrm{CH}_{3} \mathrm{SCu}+\mathrm{H}^{+}
\end{gathered}
$$

The strength of the complexes decreases in the order $\mathrm{Cu}(\mathrm{II})>\mathrm{Cu}(\mathrm{I})>\mathrm{Fe}(\mathrm{II})>\mathrm{Zn}$ (II) and $\mathrm{H}_{2} \mathrm{~S}>\mathrm{MeSH}$. Copper is a particular case as it has been demonstrated that in $\mathrm{Cu}(\mathrm{II})-$ $\mathrm{S}(-\mathrm{II})$ complexes there is a transference of charge between the $\mathrm{Cu}$ and $\mathrm{S}$ atoms, becoming temporally $\mathrm{Cu}(\mathrm{I})-\mathrm{S}(-\mathrm{I})$, as described by Luther et $\mathrm{al}^{16}$ and Kreitman et al. ${ }^{18}$ The displacement of the different complex formation/dissociation equilibria to release free forms will be most likely caused by the accumulation of large amounts 
of cysteine and glutathione formed by reduction of the corresponding disulfides accumulated when the wine has been previously in contact with oxygen:

$$
\mathrm{RSSR}+2 \mathrm{H}^{+}+2 \mathrm{e}^{-} \longrightarrow 2 \mathrm{RSH} \text { (where } \mathrm{R} \text { is Cys or Glu and the reduction is }
$$
possibly induced by the spontaneous condensation of polyphenols)

$$
\begin{gathered}
\mathrm{MS}+2 \mathrm{RSH}<\longrightarrow \text { RSMSR }+\mathrm{H}_{2} \mathrm{~S} \\
\mathrm{Cu}_{2} \mathrm{~S}+2 \mathrm{RSH}<\longrightarrow 2 \mathrm{CuSR}+\mathrm{H}_{2} \mathrm{~S}, \text { or } \\
\mathrm{Cu}-\mathrm{SH}+\mathrm{RSH}<\longrightarrow \mathrm{CuSR}+\mathrm{H}_{2} \mathrm{~S} \\
\mathrm{CH}_{3} \mathrm{SMSCH}_{3}+2 \mathrm{RSH}<\longrightarrow \text { RSMSR }+2 \mathrm{CH}_{3} \mathrm{SH} \\
\mathrm{CH}_{3} \mathrm{SCu}+\mathrm{RSH}<\longrightarrow \text { RSCu}+\mathrm{CH}_{3} \mathrm{SH}
\end{gathered}
$$

5. Wine redox potential tends spontaneously to become reductive by reasons that are not understood today. Preliminary data suggest that spontaneous polyphenol condensation reactions taking place in anoxia, could be a source of electrons which would first completely reduce $\mathrm{Fe}(\mathrm{III})$ to $\mathrm{Fe}(\mathrm{II})$ and later all disulfides and hydrodisulfides and maybe also polysulfides, hydropolysulfides, polysulfanes, to mercaptans and $\mathrm{H}_{2} \mathrm{~S}$. In this sense, the sulfur atom seems to be the ultimate sink for the electrons that wine polyphenols tend to spontaneously release. It can be hypothesized that the redox potential will drop until all S(-I) has been reduced to S(II) as long as the wine contains polyphenols able to undergo those spontaneous condensation reactions. Therefore, in the absence of oxygen, wine tends to a state of equilibrium which depends on its polyphenolic and total thiol content and which is characterized by a more or less negative redox potential at which the predominant forms will be free sulfhydryls in equilibrium with their metal complexed forms. Note that only at this negative redox potential, BR-forms represent the present total content in $\mathrm{H}_{2} \mathrm{~S}$ and $\mathrm{MeSH}$ of that wine and that $\alpha$ will be maximum, close to 1 . It can be also hypothesized that the maximum value of $\alpha$ will depend on the $\mathrm{RSH} / \mathrm{Cu}$ ratio of the wine. 
6. When the wine comes into contact with oxygen, the following set of reactions will most likely take place: ${ }^{22-24}$

$$
\begin{aligned}
& \text { a) Formation of } \mathrm{Fe}(\mathrm{III}) \\
& \mathrm{Fe}(\mathrm{II})+1 / 2 \mathrm{O}_{2}+\mathrm{H}_{2} \mathrm{O} \longrightarrow \mathrm{Fe}(\mathrm{III})+\mathrm{H}_{2} \mathrm{O}_{2}
\end{aligned}
$$

b) Oxidation of $\mathrm{Cu}(\mathrm{I})$-complexed with $\mathrm{S}(-\mathrm{II})$ - to $\mathrm{Cu}(\mathrm{II})$

$$
\begin{aligned}
& \mathrm{Fe}(\mathrm{III})+\mathrm{Cu}(\mathrm{I})-\mathrm{SH} \longrightarrow \mathrm{Fe}(\mathrm{II})+\mathrm{Cu}(\mathrm{II})-\mathrm{SH} \\
& \mathrm{Fe}(\mathrm{III})+\mathrm{Cu}(\mathrm{I})-\mathrm{SCH}_{3} \longrightarrow \mathrm{Fe}(\mathrm{II})+\mathrm{Cu}(\mathrm{II})-\mathrm{SCH}_{3} \\
& \mathrm{Fe}(\mathrm{III})+\mathrm{Cu}(\mathrm{I})-\mathrm{SR} \longrightarrow \mathrm{Fe}(\mathrm{II})+\mathrm{Cu}(\mathrm{II})-\mathrm{SR}
\end{aligned}
$$

c) Formation of $\mathrm{Cu}(\mathrm{II})-\mathrm{S}(-\mathrm{II})$ dimers

$$
\begin{aligned}
\mathrm{Cu}(\mathrm{II})-\mathrm{SH}+\mathrm{RSH} & \longrightarrow \mathrm{RS}-\mathrm{Cu}(\mathrm{II})-\mathrm{SH}+\mathrm{H}^{+} \\
\mathrm{Cu}(\mathrm{II})-\mathrm{SCH}_{3}+\mathrm{RSH} & \longrightarrow \mathrm{RS}-\mathrm{Cu}(\mathrm{II})-\mathrm{SCH}_{3}+\mathrm{H}^{+} \\
\mathrm{Cu}(\mathrm{II})-\mathrm{SR}+\mathrm{RSH} & \longrightarrow \mathrm{RS}-\mathrm{Cu}(\mathrm{II})-\mathrm{SR}+\mathrm{H}^{+}
\end{aligned}
$$

$$
\begin{gathered}
\text { d) } \text { Oxidation of } \mathrm{S}(-\mathrm{II}) \text { by } \mathrm{Cu}(\mathrm{II}) \\
\mathrm{RS}-\mathrm{Cu}(\mathrm{II})-\mathrm{SH}+\mathrm{RS}-\mathrm{Cu}(\mathrm{II})-\mathrm{SR} \longrightarrow \mathrm{Cu}(\mathrm{I})-\mathrm{SR}+\mathrm{RSSH}^{\longrightarrow} \\
\mathrm{RS}-\mathrm{Cu}(\mathrm{II})-\mathrm{SCH} \mathrm{RH}_{3}+\mathrm{RS}-\mathrm{Cu}(\mathrm{II})-\mathrm{SR} \longrightarrow \mathrm{Cu}(\mathrm{I})-\mathrm{SR}+\mathrm{RSSCH}_{3} \\
2 \mathrm{RS}-\mathrm{Cu}(\mathrm{II})-\mathrm{SR} \longrightarrow \mathrm{Cu}(\mathrm{I})-\mathrm{SR}+\mathrm{RSSR}
\end{gathered}
$$

$\mathrm{H}_{2} \mathrm{O}_{2}$ will react with $\mathrm{SO}_{2}$, the exogenous antioxidant of wine while is available, or will oxidize ethanol to produce acetaldehyde through the Fenton reaction. And if more oxygen is available, this will work in a continuous cycle as recently suggested. ${ }^{24}$

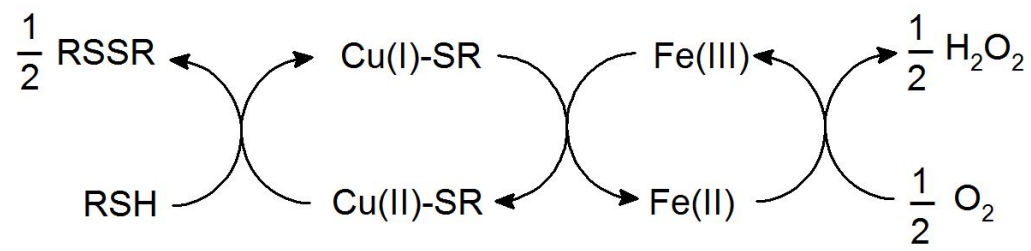

7. Even after having consumed relatively large amounts of $\mathrm{O}_{2}$, (around $20 \mathrm{mg} / \mathrm{L}$ in ref. ${ }^{23}$ ), the process can be completely reversed recovering quantitatively the initial levels of "total" $\mathrm{H}_{2} \mathrm{~S}$ if the wine is again stored in anoxic conditions long enough. This suggests that disulfides and hydrodisulfides are quite resistant to oxidation. At present it is not clear when these compounds will be eliminated by reaction with quinones ${ }^{43}$ or with other reactive oxygen species. It should be also considered that a wine containing in total $400 \mu \mathrm{M}$ of thiols, is able to consume $100 \mu \mathrm{M}$ of $\mathrm{O}_{2}(3.2 \mathrm{mg})$ and will accumulate $200 \mu \mathrm{M}$ of disulfides which will be a reservoir of oxidant able 
to slowly consume up to $400 \mu \mathrm{M}$ of electrons from polyphenols or other sources, implying a deferred oxidation over time

8. During bottle aging wine receives a little ingress of oxygen through the closure whose level depends on its specific oxygen transfer rate (OTR). The wine will reach an equilibrium point at which the rate of formation of disulfides becomes similar to the rate of their spontaneous reduction. Such equilibrium will be manifested by a specific redox potential and by the corresponding levels of BR-forms and of $\alpha$, meaning that the OTR of the closure will influence the intensity of reductive off-odors.

The previous theory contains numerous statements which are just mere hypotheses, but it seems to explain quite satisfactorily present evidence and provides a rational framework which will help to design future research. It is also clear that further progress will require a refinement of experimental techniques for characterizing and measuring the species related to $\mathrm{H}_{2} \mathrm{~S}$ and mercaptans, as well as to characterize and measure the species related to the changes in wine redox potential during anoxic storage.

Supporting Information. The detailed description of the experiments whose unpublished results are presented in Figures 4 and 5 are given as Supporting Information

\section{ACKNOWLEDGEMENTS}

This work has been funded by the Spanish MINECO (projects ALI 2014-59840, RTC2015-3379 and RTC-2016-4935-2) and partly cofunded by the European Union (FEDER). E.V. has received a grant from the Diputación General de Aragón. Funding from Diputación General de Aragón (T53) and Fondo Social Europeo is acknowledged.

\section{REFERENCES}


417 1. Siebert, T. E.; Solomon, M. R.; Pollnitz, A. P.; Jeffery, D. W., Selective 418 determination of volatile sulfur compounds in wine by gas chromatography with sulfur 419 chemiluminescence detection. J. Agric. Food Chem. 2010, 58 (17), 9454-9462.

420 2. Goode, J., Wine Science: The Application of Science in Winemaking. Mitchell Beazley Publishers Limited ed.; Mitchell Beazley: London, 2014.

3. Goode, J., Harrop, S., Wine faults and their prevalence: data from the wold's largest blind tasting. In Sulfur compounds: Production and sensory impact on wine. XXes Entretiens Scientifiques Lallemand, vol. 16 (pp. 7-9). Horsens (Denmark): Lallemand, 2008.

4. Schutz, M.; Kunkee, R. E., Formation of hydrogen-sulfide from elemental sulfur during fermentation by wine yeast. Am. J. Enol. Viticult. 1977, 28 (3), 137-144.

5. Jiranek, V.; Langridge, P.; Henschke, P. A., Regulation of hydrogen-sulfide liberation in wine-producing Saccharomyces-cerevisiae strains by assimilable nitrogen. Appl. Environ. Microbiol. 1995, 61 (2), 461-467.

6. Linderholm, A.; Dietzel, K.; Hirst, M.; Bisson, L. F., Identification of MET10932 and characterization as an allele reducing hydrogen sulfide formation in wine strains of Saccharomyces cerevisiae. Appl. Environ. Microbiol. 2010, 76 (23), 7699-7707.

7. Rauhut, D., Usage and formation of sulphur compounds. In Biology of Microorganisms on Grapes, in Must and in Wine, Springer-Verlag, Berlin 2009 (pp. 181207).

8. Waterhouse, A., Sacks, G. L., \& Jeffery, D. W. Understanding wine chemistry. Chichester, West Sussex: John Wiley \& Sons. 2016.

9. Bekker, M.; Day, M.; Holt, H.; Wilkes, E.; Smith, P., Effect of oxygen exposure during fermentation on volatile sulfur compounds in Shiraz wine and a comparison of strategies for remediation of reductive character. Aust. J. Grape Wine Res. 2016, 22 (1), 24-35.

10. Clark, A. C.; Grant-Preece, P.; Cleghorn, N.; Scollary, G. R., Copper(II) addition to white wines containing hydrogen sulfide: residual copper concentration and activity. Aust. J. Grape Wine Res. 2015, 21 (1), 30-39.

11. Ugliano, M.; Kwiatkowski, M. J.; Travis, B.; Francis, I. L.; Waters, E. J.; Herderich, M. J.; Pretorius, I. S., Post-bottling management of oxygen to reduce offflavour formation and optimize wine style. Aust. N.Z. Wine Ind. 2009, 24 (5), 24-28.

12. Vela, E.; Hernández-Orte, P.; Franco-Luesma, E.; Ferreira, V., The effects of copper fining on the wine content in sulfur off-odors and on their evolution during accelerated anoxic storage. Food Chem. 2017, 231, 212-221.

13. Viviers, M. Z.; Smith, M. E.; Wilkes, E.; Smith, P., Effects of five metals on the evolution of hydrogen sulfide, methanethiol, and dimethyl sulfide during anaerobic storage of Chardonnay and Shiraz wines. J. Agric. Food Chem. 2013, 61 (50), 1238512396.

14. Ugliano, M.; Kwiatkowski, M.; Vidal, S.; Capone, D.; Siebert, T.; Dieval, J. B.; Aagaard, O.; Waters, E. J., Evolution of 3-mercaptohexanol, hydrogen sulfide, and methyl mercaptan during bottle storage of Sauvignon blanc wines. Effect of glutathione, copper, oxygen exposure, and closure-derived oxygen. J. Agric. Food Chem. 2011, 59 (6), 2564-2572.

461 15. Godden, P., Francis, L., Field, J., Gishen, M., Coulter, A., Valente, P., Hoj, P., 462 Robinson, E., Wine bottle closures: physical characteristics and effect on composition 463 and sensory properties of a Semillon wine - 1. Performance up to 20 months post-bottling. 464 Aust. J. Grape Wine Res. 2001, 7(2), 62-105. 
465 16. Luther, G. W.; Theberge, S. M.; Rozan, T. F.; Rickard, D.; Rowlands, C. C.; 466 Oldroyd, A., Aqueous copper sulfide clusters as intermediates during copper sulfide 467 formation. Environ. Sci. Technol. 2002, 36 (3), 394-402.

468 17. Luther, G. W.; Rickard, D. T., Metal sulfide cluster complexes and their 469 biogeochemical importance in the environment. J. Nanopart. Res. 2005, 7 (6), 713-733.

470 18. Kreitman, G. Y.; Danilewicz, J. C.; Jeffery, D. W.; Elias, R. J., Reaction 471 mechanisms of metals with hydrogen sulfide and thiols in model wine. Part 1: Copper472 Catalyzed Oxidation. J. Agric. Food Chem. 2016, 64 (20), 4095-4104.

473 19. Chen, Y.; Jastrzembski, J. A.; Sacks, G. L., Copper-Complexed hydrogen sulfide 474 in wine: measurement by gas detection tubes and comparison of release approaches. Am. 475 J. Enol. Viticult. 2017, 68 (1), 91-99.

476 20. Franco-Luesma, E.; Ferreira, V., Quantitative analysis of free and bonded forms 477 of volatile sulfur compouds in wine. Basic methodologies and evidences showing the 478 existence of reversible cation-complexed forms. J. Chromatogr. A 2014, 1359, 8-15.

479 21. Franco-Luesma, E.; Ferreira, V., Reductive off-odors in wines: Formation and 480 release of $\mathrm{H}_{2} \mathrm{~S}$ and methanethiol during the accelerated anoxic storage of wines. Food 481 Chem. 2016, 199, 42-50.

482 22. Kreitman, G. Y.; Danilewicz, J. C.; Jeffery, D. W.; Elias, R. J., Copper(II)483 Mediated hydrogen sulfide and thiol oxidation to disulfides and organic polysulfanes and 484 their reductive cleavage in wine: mechanistic elucidation and potential applications. $J$. 485 Agric. Food Chem. 2017, 65 (12), 2564-2571.

486 23. Vela, E.; Franco-Luesma, E.; Hernandez-Orte, P.; Ferreira, V., Micro487 oxygenation does not eliminate $\mathrm{H}_{2} \mathrm{~S}$ and mercaptans from wine; simply shifts redox and 488 complex-related equilibria to reversible oxidized species and complexed forms. Food 489 Chem. 2017, In press FOCH 21791

490 24. Kreitman, G. Y.; Danilewicz, J. C.; Jeffery, D. W.; Elias, R. J., Reaction 491 mechanisms of metals with hydrogen sulfide and thiols in model wine. Part 2: Iron- and 492 Copper-Catalyzed Oxidation. J. Agric. Food Chem. 2016, 64 (20), 4105-4113.

493 25. Rauhut, D.; Kurbel, H.; Macnamara, K.; Grossmann, M., Headspace GC-SCD 494 Monitoring of Low Volatile Sulfur-Compounds During Fermentation and in Wine. 495 Analusis 1998, 26 (3), 142-145.

496 26. Herszage, J.; Ebeler, S. E., Analysis of volatile organic sulfur compounds in wine 497 using headspace solid-phase microextraction gas chromatography with sulfur 498 chemiluminescence detection. Am. J. Enol. Viticult. 2011, 62 (1), 1-8.

499 27. Fang, Y.; Qian, M. C., Sensitive quantification of sulfur compounds in wine by 500 headspace solid-phase microextraction technique. J. Chromatogr. A 2005, 1080 (2), 177 501185.

502 28. Lopez, R.; Lapena, A. C.; Cacho, J.; Ferreira, V., Quantitative determination of 503 wine highly volatile sulfur compounds by using automated headspace solid-phase 504 microextraction and gas chromatography-pulsed flame photometric detection - Critical 505 study and optimization of a new procedure. J. Chromatogr. A 2007, 1143 (1-2), 8-15.

506 29. Franco-Luesma, E.; Ferreira, V., Formation and release of $\mathrm{H}_{2} \mathrm{~S}$, methanethiol 507 and dimethylsulfide during the anoxic storage of wines at room temperature. J. Agric.

508 Food Chem. 2016, 64 (32), 6317-6326.

509 30. Ferreira, V.; Bueno, M.; Franco-Luesma, E.; Cullere, L.; Fernandez-Zurbano, P., 510 Key Changes in Wine Aroma Active Compounds during Bottle Storage of Spanish Red 511 Wines under Different Oxygen Levels. J. Agric. Food Chem. 2014, 62 (41), 1001551210027. 
513 31. Gruenwedel, D. W.; Patnaik, R. K., Release of hydrogen sulfide and methyl 514 mercaptan from sulfur-containing amino acids. J. Agric. Food Chem. 1971, 19 (4), $775-$ 5159.

516 32. Tomlinson, J. W.; Kilmartin, P. A., Measurement of the redox potential of wine. 517 J. Appl. Electrochem. 1997, 27 (10), 1125-1134.

518 33. Kilmartin, P. Re-evaluation of redox potential measurements in wine. 519 enoreports.com [Online], 2010.

520 34. Eshel, G.; Banin, A., Feasibility study of long-term continuous field measurement 521 of soil redox potential. Commun. Soil Sci. Plant Anal. 2002, 33 (5-6), 695-709.

522 35. Grundl, T. J.; Macalady, D. L., Electrode measurement of redox potential in 523 anaerobic ferric/ferrous chloride systems. J. Contam. Hydrol. 1989, 5 (1), 97-117.

524 36. Vivas A.; Glories, Y. B., A.; Zamora, F., Principe et méthode de mesure du 525 potentiel d'oxydoréduction dans les vins. Bulletin de l'OIV 1996, 785-786, 618-633.

526 37. Vivas, A.; Zamora, F.; Glories, Y., Étude des phénomenes d'oxydoreduction dans 527 les vins. Mise au point d'une méthode rapide de mesure du potentiel d'oxydorreduction. 528 J. Int. Sci. du Vigne Vin 1992, 26, 271-285.

529 38. Kilmartin, P. A.; Zou, H. L., The effect of electrode material on the measured 530 redox potential of red and white wines. Electroanalysis 2001, 13 (16), 1347-1350.

531 39. Danilewicz, J. C., Fe(II):Fe(III) ratio and redox status of white wines. Am. J. Enol. 532 Viticult. 2016, 67 (2), 146-152

533 40. Danilewicz, J. C., Review of oxidative processes in wine and value of reduction 534 potentials in enology. Am. J. Enol. Viticult. 2012, 63 (1), 1-10.

535 41. Fulcrand, H.; Duenas, M.; Salas, E.; Cheynier, V., Phenolic reactions during 536 winemaking and aging. Am. J. Enol. Viticult. 2006, 57 (3), 289-297.

537 42. Rozan, T. F.; Lassman, M. E.; Ridge, D. P.; Luther, G. W., Evidence for iron, 538 copper and zinc complexation as multinuclear sulphide clusters in oxic rivers. Nature 539 2000, 406 (6798), 879-882.

540 43. Nikolantonaki, M.; Waterhouse, A. L., A method to quantify quinone reaction 541 rates with wine relevant nucleophiles: a key to the understanding of oxidative loss of 542 varietal thiols. J. Agric. Food Chem. 2012, 60 (34), 8484-8491. 


\section{$543 \quad$ Figure captions}

544 Figure 1. Evolution of the fraction of $\mathrm{H}_{2} \mathrm{~S}$ and $\mathrm{MeSH}$ under free forms ( $\alpha$, in \%) during the

545 accelerated anoxic storage of red wines. Built with data from reference. ${ }^{21}$ Data are the mean of 16

546 different wines

547 Figure 2. Evolution of $\mathrm{BR}-\mathrm{H}_{2} \mathrm{~S}$ during the accelerated anoxic storage of three young red wines

548 made with tempranillo (W1 from Ribera-Duero from ref, ${ }^{21} \mathrm{~W} 2$ from Rioja was previously micro-

549 oxygenated). W2_Cu is W2 treated with $0.5 \mathrm{mg} / \mathrm{L}_{\text {of }} \mathrm{CuSO}_{4}{ }^{12}$

550 Figure 3. Effect of metal cations on the formation of BR- $\mathrm{H}_{2} \mathrm{~S}$ and BR-MeSH during 2 weeks of

551 AR-aging in wine models $(11 \% \mathrm{v} / \mathrm{v}$ ethanol, $3 \mathrm{~g} / \mathrm{L}$ glycerol, $5 \mathrm{~g} / \mathrm{L}$ tartaric acid, $\mathrm{pH} 3.5,50 \mathrm{mg} / \mathrm{L}$

552 of gallic acid and of catechin, $20 \mathrm{mg} / \mathrm{L}$ of caffeic acid) containing $20 \mathrm{mg} / \mathrm{L}$ of L-Cys and L-Met.

553 Metal cation concentration: $\mathrm{Cu}(\mathrm{II}), 0.5 \mathrm{mg} / \mathrm{L} ; \mathrm{Fe}(\mathrm{II}), 2 \mathrm{mg} / \mathrm{L} ; \mathrm{Al}(\mathrm{III}), 1 \mathrm{mg} / \mathrm{L} ; \mathrm{Mn}(\mathrm{II}), 0.8 \mathrm{mg} / \mathrm{L}$;

$554 \mathrm{Zn}(\mathrm{II}), 0.6 \mathrm{mg} / \mathrm{L}$. Experimental details given as SP.

555 Figure 4. Effect of the level of Cysteine on the redox potential of wine models (12\% ethanol, 5

$556 \mathrm{~g} / \mathrm{L}$ tartaric acid, pH 3.5) containing or not $5 \mathrm{mg} / \mathrm{L} \mathrm{Fe}(\mathrm{II}), 0.6 \mathrm{mg} / \mathrm{L} \mathrm{Cu}(\mathrm{II})$ or $0.6 \mathrm{mg} / \mathrm{L} \mathrm{Cu}(\mathrm{I})$. All

557 the models were carefully prepared in the anoxic chamber with Ar-bubbled solutions. Potentials

558 were measured after $15 \mathrm{~min}$, except the one containing just $\mathrm{Fe}(\mathrm{II})$, which required 2 days of 559 stabilization. Experimental details given as SP.

560 Figure 5. Plots relating the ratio [reduced form]/[oxidized + reduced forms] to the redox potential

561 in 4 different wine model systems, three containing different ratios of the $\mathrm{Fe}(\mathrm{II}) / \mathrm{Fe}(\mathrm{III})$ redox

562 pair, and one of the Cysteine/Cystine. All models contained ethanol, $5 \mathrm{~g} / \mathrm{L}$ tartaric acid with $\mathrm{pH}$

5633.5 and $5.0 \mathrm{mg} / \mathrm{L}$ of total iron. Iron pairs: $14 \%(\mathrm{v} / \mathrm{v})$ ethanol; $12 \%$ ethanol, $1 \mathrm{~g} / \mathrm{L}$ citric acid; $14 \%$

564 ethanol, $1 \mathrm{~g} / \mathrm{L}$ citric acid $+1 \mathrm{~g} / \mathrm{L}$ glutamic acid. Cysteine/Cystine pair: $12 \%$ ethanol, $45 \mathrm{mg} / \mathrm{L}$

565 Cys+Cystine, $5.0 \mathrm{mg} / \mathrm{L} \mathrm{Fe}(\mathrm{II})$. Experimental details given as SP.

566 Figure 6: Evolution of the average redox potential of 15 red wines and 8 whites and rosés stored

567 in strict anoxia at $50^{\circ} \mathrm{C}$. Error bars are standard errors of the corresponding means. Data taken

568 from the work presented in ref. ${ }^{21}$ 
569 Figure 7. Relationship between the $\mathrm{BR}-\mathrm{H}_{2} \mathrm{~S}$ level of a wine and its redox potential. Data 570 correspond to a red wine made from Syrah subjected to tree different MOX treatments. Initial 571 wine and the three MOX samples were further subjected to AR-aging ( 2 and 7 weeks)

572 Figure 8. Plot showing the relationship between the average redox potential of 16 red wines 573 stored at $50^{\circ} \mathrm{C}$ and the $\alpha$ fraction of $\mathrm{H}_{2} \mathrm{~S}$ present as free forms (expressed as $\%$ of BR-forms).

574 Error bars are the standard error of the means. Numbers indicate the AR-aging time in days 
Table 1. PLS models explaining increases in $\mathrm{BR}$-forms of $\mathrm{H}_{2} \mathrm{~S}$ and $\mathrm{MeSH}$, in their corresponding proportions in free forms $(\alpha)$ and decreases in the redox potential during the anoxic storage of wines. These models have been built from data presented in reference. ${ }^{21}$ Positively correlated compounds are boldfaced. Abbreviations are given in the legend

\begin{tabular}{|c|c|c|c|c|}
\hline $\mathrm{N}^{\mathrm{o}}$ & Wine type/Parameter & EVar & RMSE & Model (regression coefficients) \\
\hline 1 & $\begin{array}{l}\text { Red wines. De novo } \\
\text { formation of } \mathrm{H}_{2} \mathrm{~S}\end{array}$ & $90 \% *$ & 0.76 & $\begin{array}{l}-0.31+\mathbf{0 . 2 2 4} \text { LPP }+\mathbf{0 . 2 2 7} \\
\text { Isorhamnetin }+\mathbf{0 . 1 9 7} \text { Vitisin A + } \\
\mathbf{0 . 1 7 7} \text { Cysteine }+\mathbf{0 . 1 6 3} \\
\text { Pyranoanthocyanins }-0.182 \\
\text { epigallocatechin (thiolysis) }-0.169 \\
\text { proanthocyanidins }\end{array}$ \\
\hline 2 & $\begin{array}{l}\text { Whites and Rosés. Rate } \\
\text { of increase of BR- } \mathrm{H}_{2} \mathrm{~S} \\
\text { (de novo formation rate) }\end{array}$ & $97 \%$ & 0.021 & $\begin{array}{l}3.44+\mathbf{0 . 4 0 2} \mathbf{~ F e}+\mathbf{0 . 1 6 7} \mathbf{C u}+\mathbf{0 . 1 0 4} \\
\text { Cysteine }-0.27 \mathrm{Mn}-0.27 \mathrm{Al}- \\
0.225 \text { freeSO } \\
2\end{array}$ \\
\hline 3 & $\begin{array}{l}\text { Red wines. Rate of } \\
\text { increase of BR-MeSH } \\
\text { (de novo formation rate) }\end{array}$ & $88 \% *$ & 0.0059 & $\begin{array}{l}7.03+\mathbf{0 . 1 4 9} \text { Methionine }+\mathbf{0 . 1 6 4} \\
\text { Ethyl caffeate }+\mathbf{0 . 1 7 0} \\
\text { Procyanidin A2 }-0.134 \text { Initial } \\
\text { redox potential }-0.125 \mathrm{MP}-0.152 \\
\text { EC4b }-0.12 \mathrm{ECG}-0.152 \\
\text { Procyanidins }-0.152 \mathrm{pH}\end{array}$ \\
\hline 4 & $\begin{array}{l}\text { White and rosé wines. } \\
\text { Rate of increase of BR- } \\
\text { MeSH (de novo } \\
\text { formation rate) }\end{array}$ & $91 \%$ & 0.011 & $\begin{array}{l}0.11+\mathbf{0 . 0 1 6} \text { Methionine }+\mathbf{0 . 0 1 1 3} \\
\mathbf{Z n}+\mathbf{0 . 0 1 4 2} \mathbf{~ p H}-0.0199 \mathrm{Mn}- \\
0.010 \text { Initial redox potential }\end{array}$ \\
\hline 7 & $\begin{array}{l}\text { Red wines. } \\
\text { Increase of free } \mathrm{H}_{2} \mathrm{~S} \text { in } \\
21 \text { days }\end{array}$ & $77 \%$ & 2.94 & $\begin{array}{l}3.27+\mathbf{0 . 2 1 6} \mathbf{B R}-\mathbf{H}_{2} \mathbf{S} / \mathbf{C u}+\mathbf{0 . 1 5 5} \\
\mathbf{Z n}-\mathbf{0 . 2 3 3} \text { Final redox potential } \\
-0.247 \text { trans-aconitic acid }-0.237 \\
\mathrm{Cu}-0.151 \text { Malvidin-3-O-glucoside } \\
-0.141 \mathrm{~A} 620\end{array}$ \\
\hline 8 & $\begin{array}{l}\text { Whites \& Rosés wines. } \\
\text { Increase of free } \mathrm{H}_{2} \mathrm{~S} \\
\text { exclusively due to } \\
\text { release from complexes }\end{array}$ & $93 \%$ & 1.02 & $\begin{array}{l}5.64+\mathbf{0 . 3 3 2} \mathbf{B R}-\mathbf{H}_{2} \mathbf{S} / \mathbf{C u}-\mathbf{0 . 2 1 2} \\
\Delta \mathbf{V m a x} \mathbf{m}^{\mathrm{a}}-0.427 \text { Folin }-0.272 \mathrm{t}- \\
\text { coumaric acid }-0.227 \text { vanillic acid }\end{array}$ \\
\hline 9 & $\begin{array}{l}\text { Red wines. } \\
\text { Increase of free } \mathrm{MeSH} \\
\text { exclusively due to its } \\
\text { release from complexes }\end{array}$ & $87 \%$ & 0.179 & $\begin{array}{l}1.65+\mathbf{0 . 4 1 5} \mathbf{M e S H}_{\text {complexed }} / \mathbf{C u}+ \\
\mathbf{0 . 4 5 7} \mathbf{M e S H}_{\text {complexed }}-0.257 \mathrm{SPP}\end{array}$ \\
\hline 10 & $\begin{array}{l}\text { White \& Rosés wines. } \\
\text { Increase of free MeSH } \\
\text { exclusively due to its } \\
\text { release from complexes }\end{array}$ & $88 \%$ & 0.127 & $\begin{array}{l}-0.324+\mathbf{0 . 2 6 3} \mathrm{MeSH}_{\text {complexed }}+ \\
\mathbf{0 . 2 3 9} \mathrm{MeSH}_{\text {complexed }} / \mathrm{Cu}+\mathbf{0 . 2 2 1} \\
\text { TPI }+\mathbf{0 . 2 4 1} \mathbf{M y r G a l}_{-0.222 \mathrm{Al}}\end{array}$ \\
\hline \multicolumn{5}{|c|}{$\begin{array}{l}\text { *two samples excluded; \#one sample excluded } \\
{ }^{a} \text { Since redox potential becomes more negative during the storage, the minus sign indicates that } \\
\text { a higher drop implies higher release } \\
\text { Abbreviations: LPP, large polymeric pigments; MP, mono pigments; EC4b, Epicatechin-4b- } \\
\text { benyzlthioether; ECG, epicatechin-3-O-gallate; SPP, small polymeric pigments; mDP, mean } \\
\text { degree of polymerization; TPI, total polyphenol index; MyrGal, Myricetin-3-galactoside }\end{array}$} \\
\hline
\end{tabular}


Figure 1

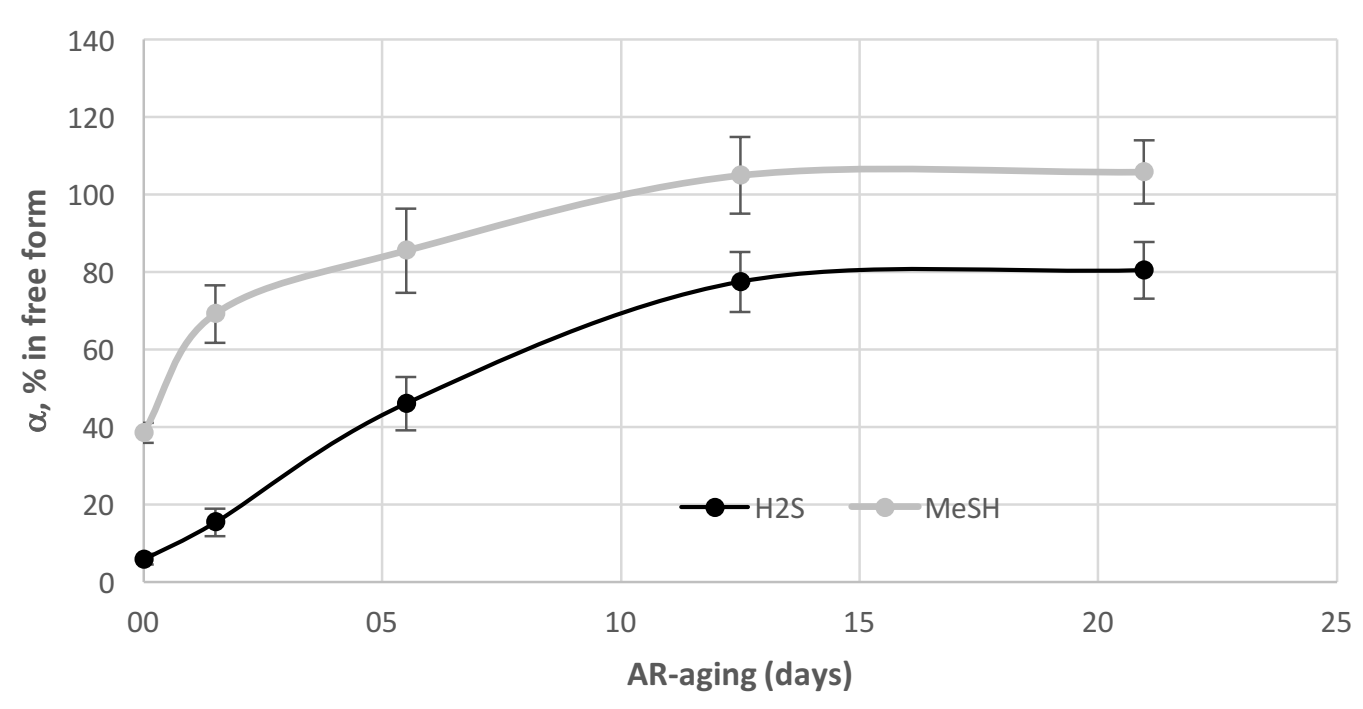

Figure 2

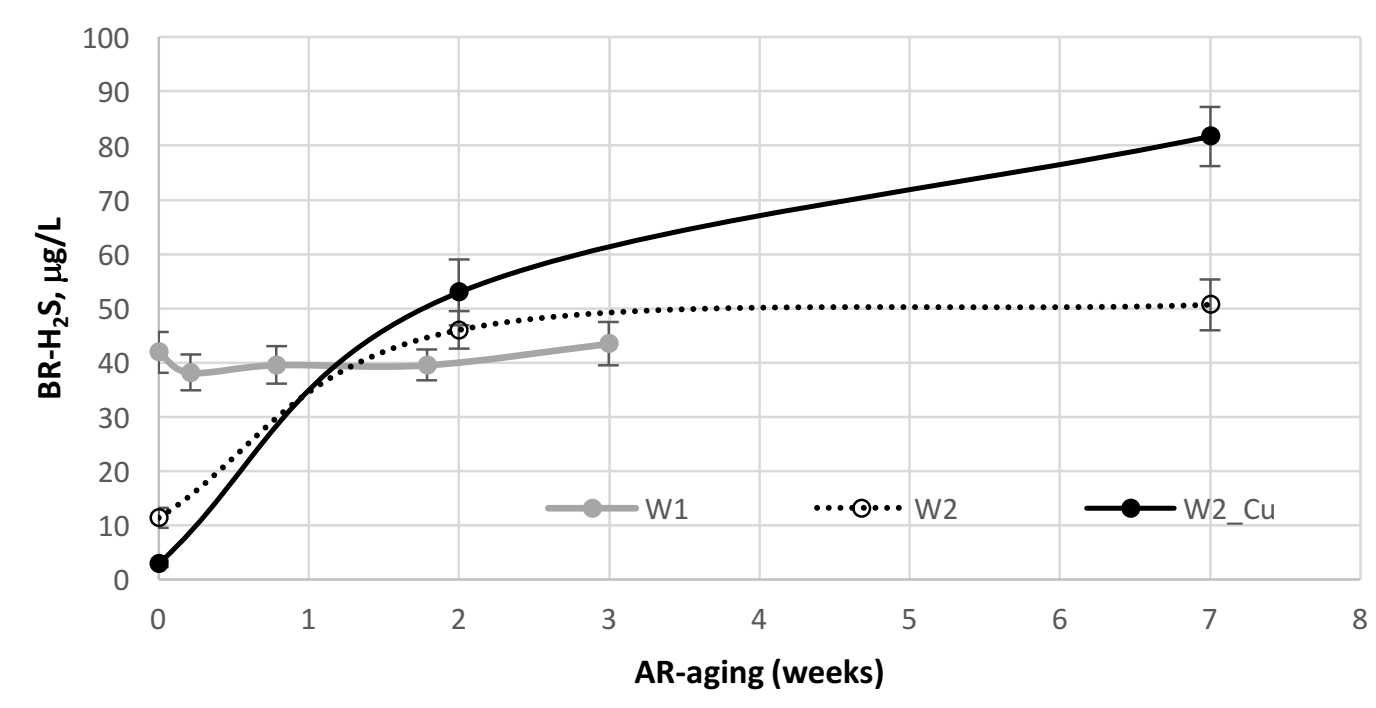


Figure 3

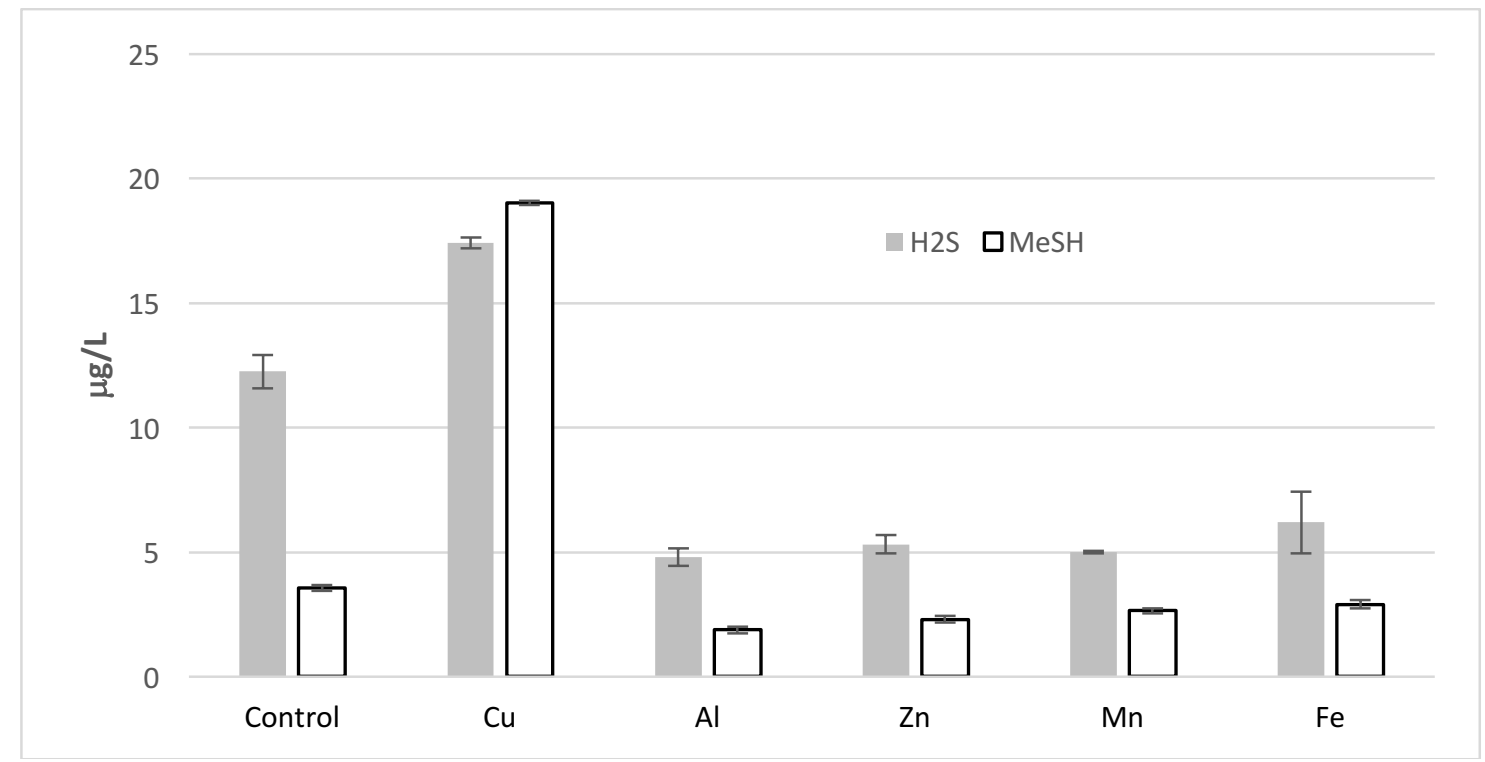

Figure 4

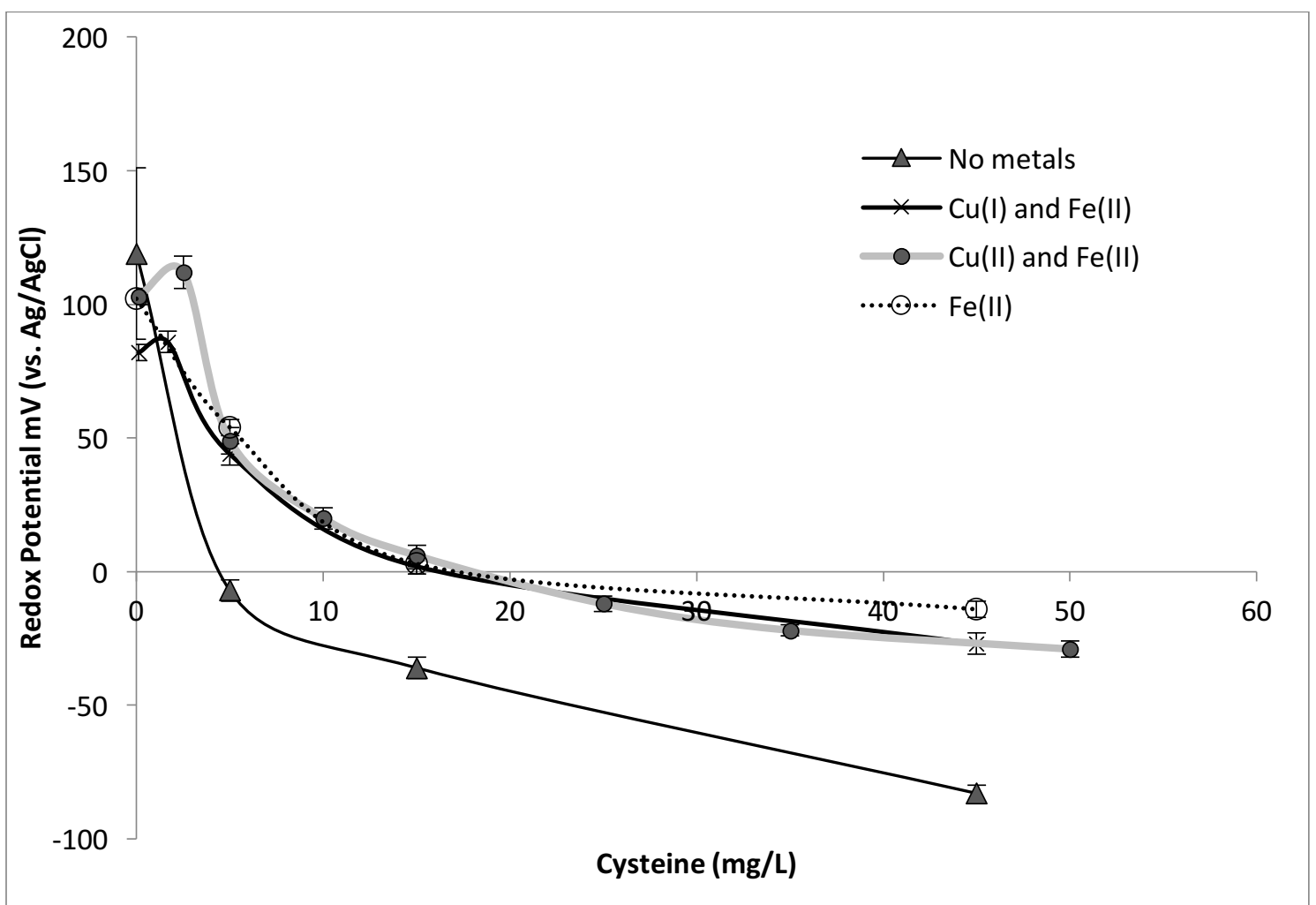


Figure 5

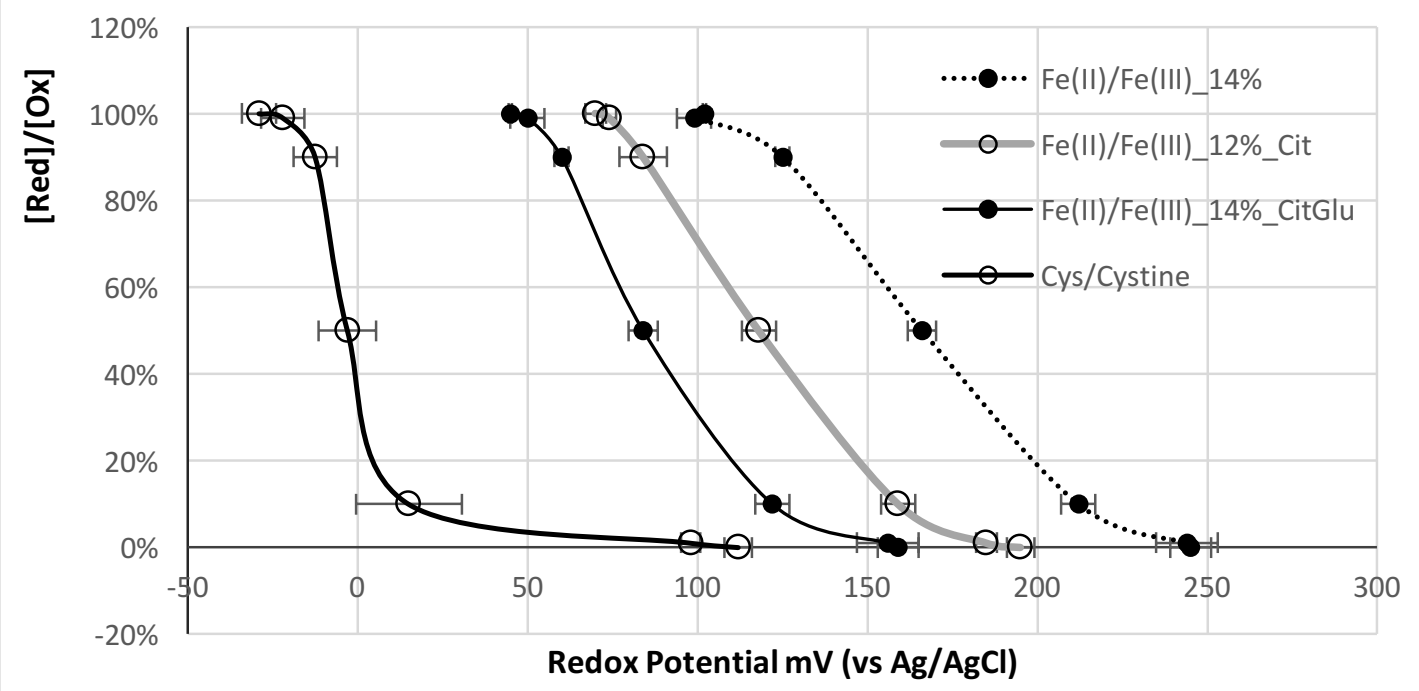

Figure 6

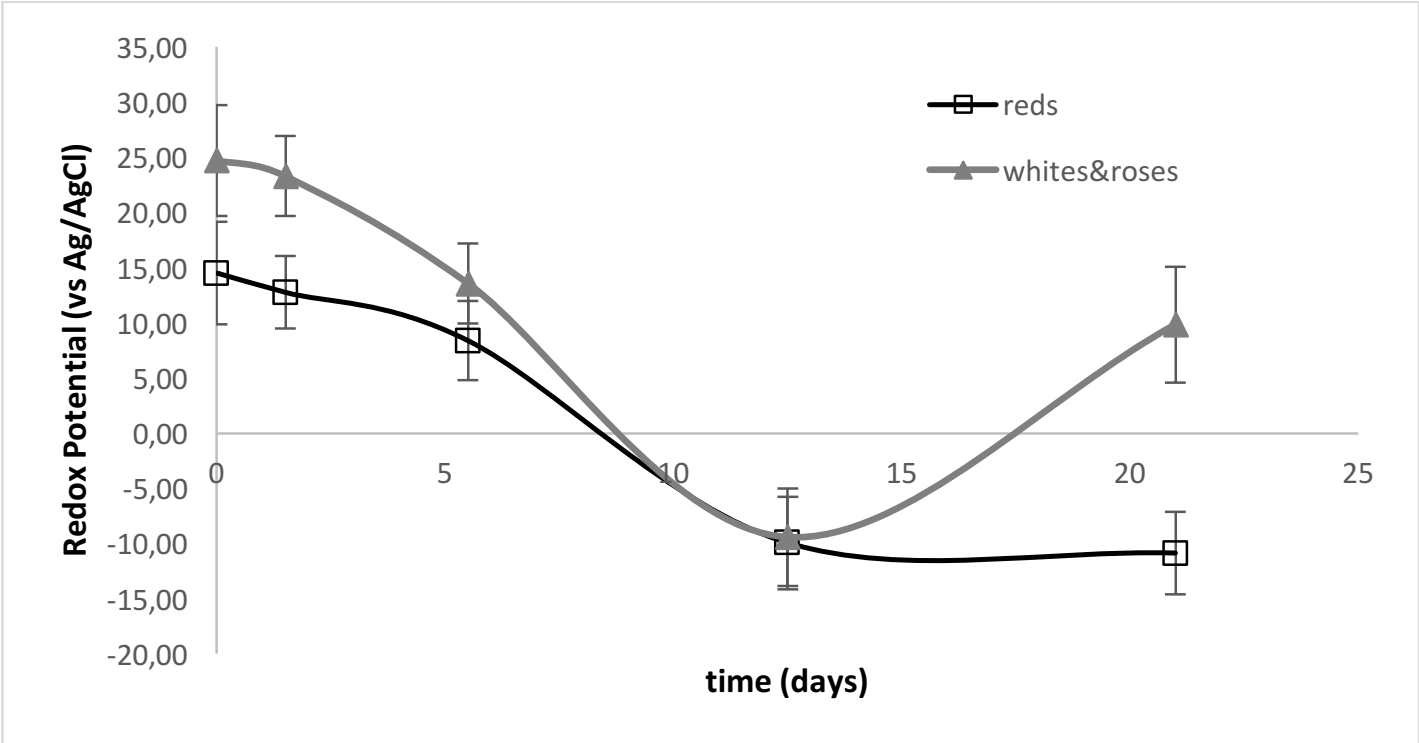


Figure 7

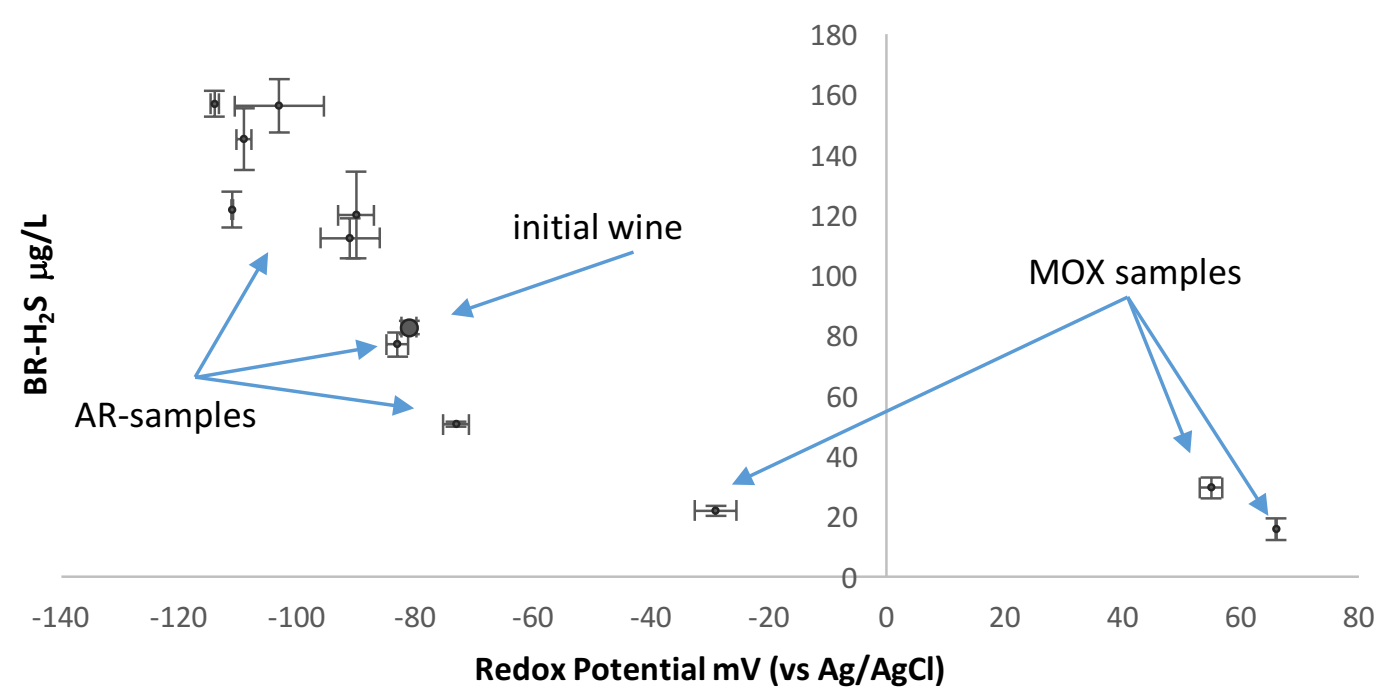

Figure 8

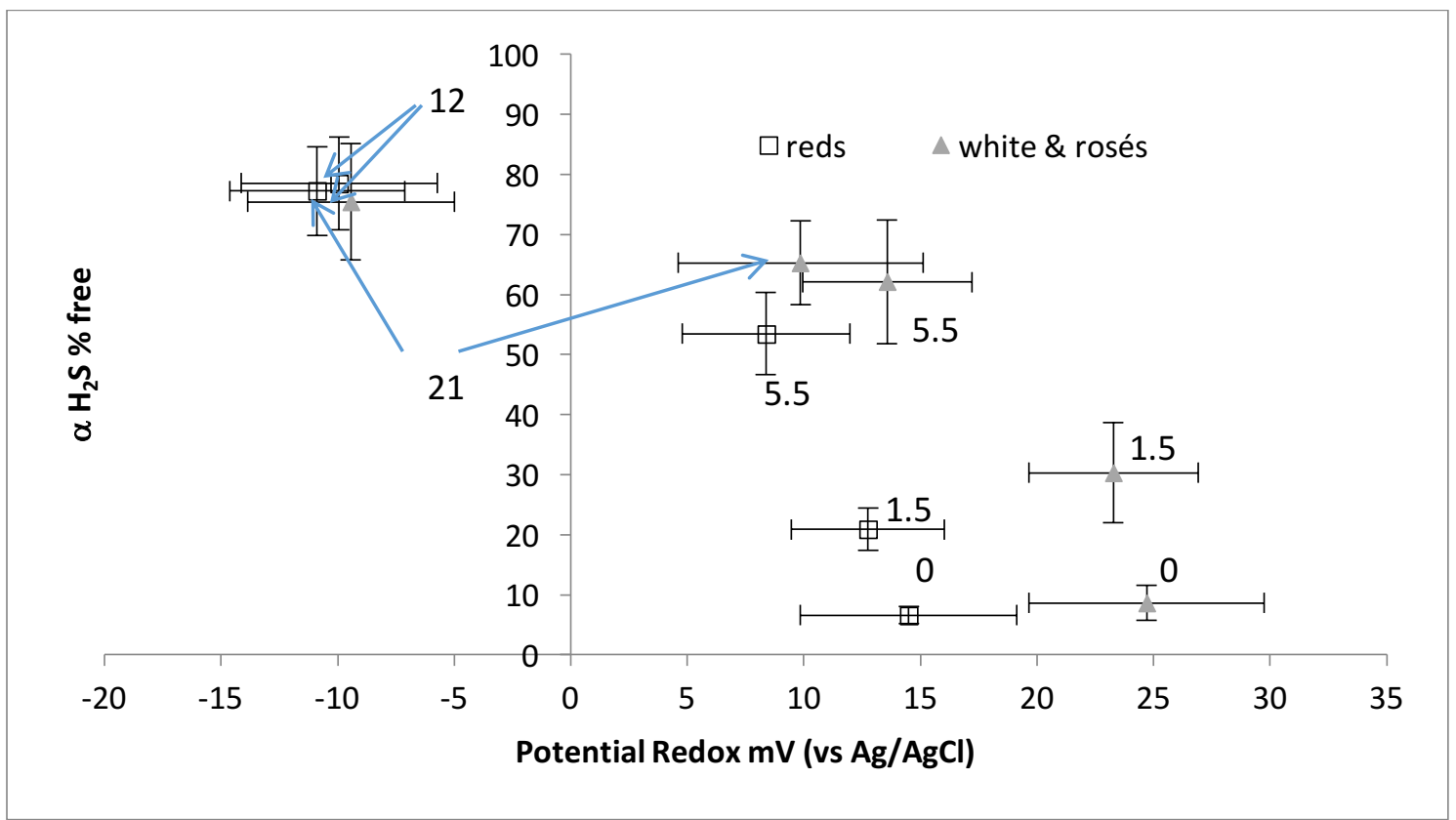

